\title{
Uterine Arteriovenous Malformation
}

\author{
Yuksel OGUZ1, Fatma GONCA ELDEM², Barbaros CIL ${ }^{2}$, Cem SANHAL ${ }^{1}$, \\ Gulenay GENCOSMANOGLU TURKMEN', Aykan YUCEL'1, Dilek UYGUR ${ }^{1}$
}

Ankara, Turkey

\section{ABSTRACT}

We aimed to report a case of uterine arteriovenous malformation which was successfully treated by uterine artery embolization.

A multiparous 23-year-old woman referred to our clinic for 7 weeks of scar pregnancy. On ultrasound, incisional $32 \times 37 \mathrm{~mm}$ gestational sac surrounded with non-pulsatile high flow vessels was demonstrated. Uterine artery embolization was performed with Gelfoam by interventional radiology. The post-embolization arteriogram showed complete embolization of the uterine arteriovenous malformation with a slow flow of contrast in both uterine arteries.

In clinical suspicion, uterine arteriovenous malformation can be diagnosed with Doppler ultrasonography and can be treated successfully with either uterine artery embolization or uterine surgery. Uterine arteriovenous malformation is commonly diagnosed in women of childbearing age, angiographic embolization should be the firstly preferred treatment.

Keywords: Arteriovenous malformation, Embolization, Scar pregnancy

Gynecol Obstet Reprod Med 2019;25(1):59-61

\section{Introduction}

Uterine arteriovenous malformation (UAVM) is a rare condition which can be life - threatening when presenting with severe bleeding. There are fewer than 100 cases reported in the literature. UAVMs can be congenital or acquired. Congenital type UAVM is very rare, and it results from developmental abnormalities of uterine vessels. Acquired type is more common, and may develop after pelvic surgery, endometrial carcinomas, miscarriage, uterine infections, leiomyomas, endometriosis, intrauterine devices and gestational trophoblastic diseases $(1,2)$. Doppler ultrasonography and com-

${ }^{1}$ Department of High Risk Pregnancy, University of Heath Sciences, Zekai Tahir Burak Women's Health Education and Research Hospital, Ankara

${ }^{2}$ Department of Radiology, Hacettepe University School of Medicine, Ankara

Address of Correspondence: Yuksel Oguz

University of Heath Sciences, Zekai

Tahir Burak Women's Health Education and Research Hospital, 06230 Ankara,

Turkey

yksloguz@hotmail.com

Submitted for Publication: 24. 11. 2017

Accepted for Publication: $\quad$ 13. 02. 2017

ORCID IDs of the authors:

Y.O: 0000-0002-9303-9355, F.GE.: 0000-0002-9887-4018,

B.C.: 0000-0003-1079-0088, C.S.: 0000-0003-0007-5769,

G.GT:: 0000-0002-0826-5252, A.Y.: 0000-0002-5888-692X, D.U.: 0000-0001-8567-9048

\begin{tabular}{|c|c|}
\hline Quick Response Code: & Access this article online \\
\cline { 2 - 2 } & Website: www.gorm.com.tr \\
& e- mail: info@gorm.com.tr \\
\cline { 2 - 3 } & DOI:10.21613/GORM.2018.776 \\
\hline
\end{tabular}

How to cite this article: Oguz Y. Gonca Eldem F. Cil B. Sanhal C. Gencosmanoglu Turkmen G. Aykan Y. Dilek U. Uterine Arteriovenous Malformation Pregnancy: Case Report. Gynecol Obstet Reprod Med 2019;25(1):59-61 puterized tomography $(\mathrm{CT})$ or magnetic resonance (MR) angiography are generally used for diagnosis. Treatment options are uterine artery embolization and uterine surgery (3-7). In this case report, we presented a 7-week pregnant woman with acquired UAVM secondary to the previous cesarean section which was successfully treated with uterine artery embolization. Informed consent was taken from the patient.

\section{Case Report}

A multiparous 23-year-old woman with a history of previous two cesarean sections, referred to our clinic for 7 weeks scar pregnancy. The patient was hospitalized. Except for cesarean section, she had no uterine surgery in her medical history. On Doppler ultrasonography, an incisional $32 \times 37 \mathrm{~mm}$ gestational sac, and non-pulsatile high flow vessels were demonstrated in the endometrial cavity (Figure 1,2). The patient was hemodynamically stable with no uterine bleeding. She was consulted to the radiology department for the evaluation of a suspected UAVM, and scheduled for an MR. MR angiography was performed subsequently showing that the UAVM was supplied by bilateral uterine arteries (UA), mainly from the left UA, with some vessels proceeding from the contralateral UA. Uterine artery embolization was performed with Gelfoam by department of interventional radiology (Figure 3). Methotrexate (Methotrexate ${ }^{\circledR}$, Kocak Farma, Turkey), $50 \mathrm{mg}$ IM was administered only once, as there was also concomitant scar pregnancy. The post-embolization arteriogram showed complete embolization of the UAVM with a slow flow of contrast in both uterine arteries. Post-embolization ultrasound examination revealed distorted gestational sac. During follow-up, $\beta$ - hCG results showed a gradual decrease. The patient was discharged from hospital at post-embolization 40 day (Figure 4). 


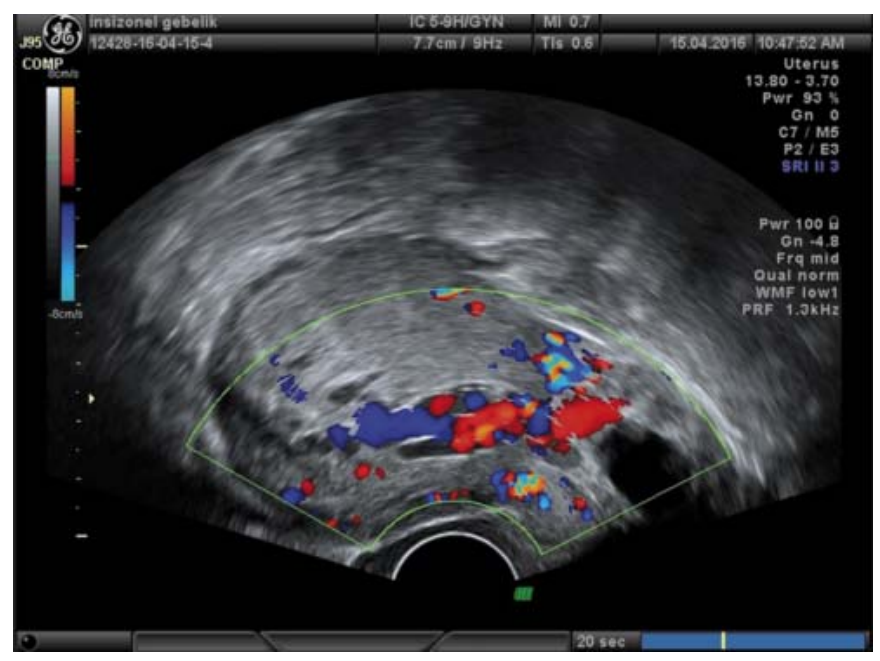

Figure 1: Incisional gestational sac and uterine arteriovenous malformation

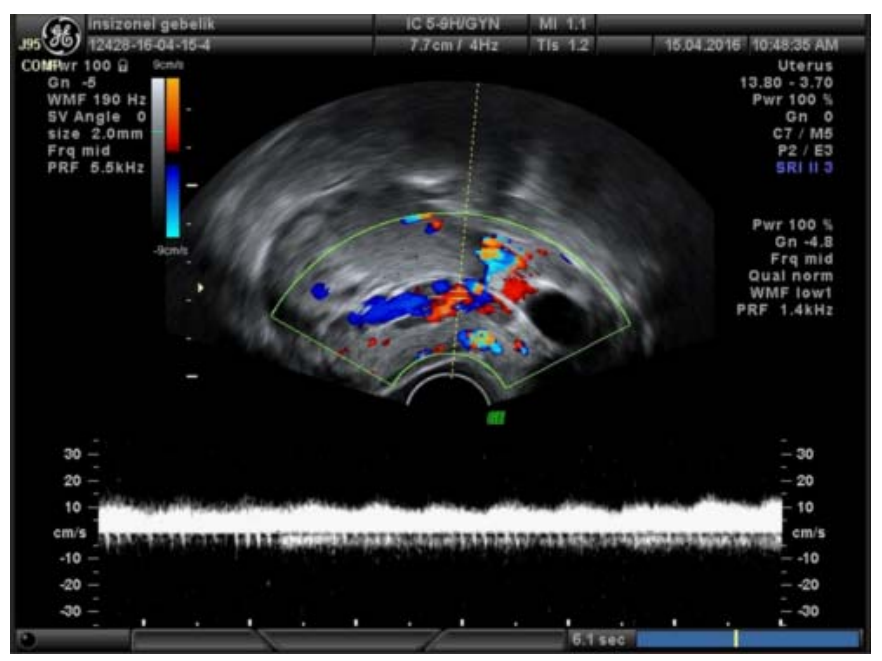

Figure 2: Non-pulsatile high flow vessels were demonstrated.
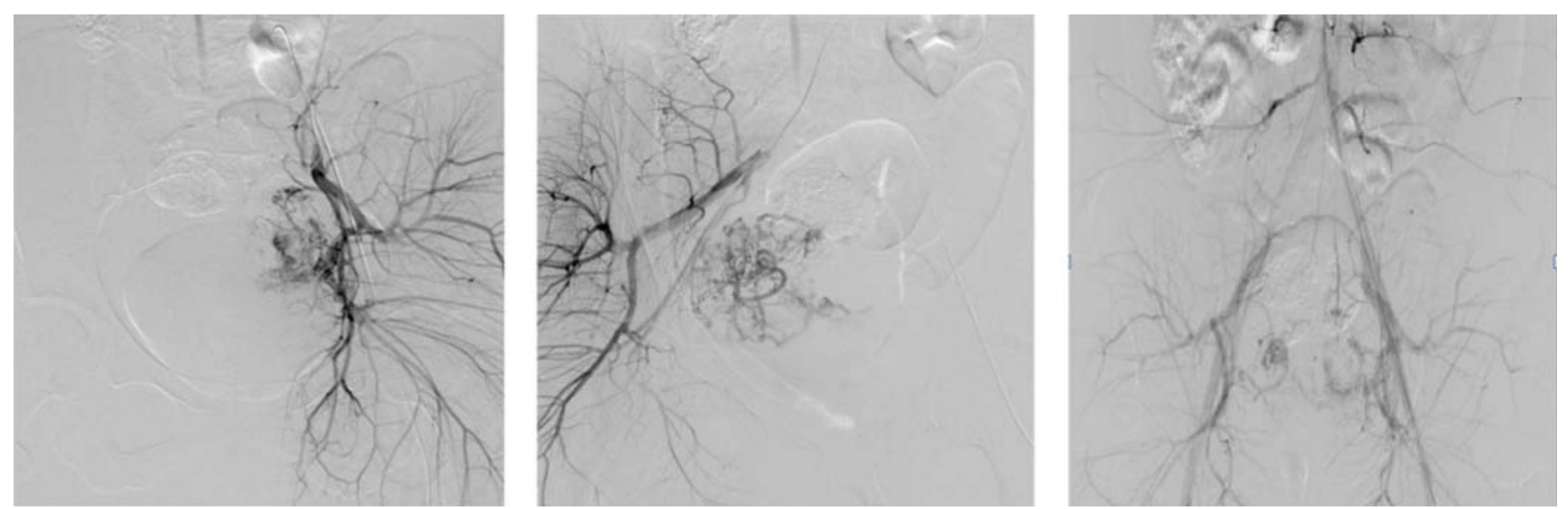

Figure 3: The post-embolization arteriogram showed complete embolization of the AVM with slow flow of contrast in both uterine arteries

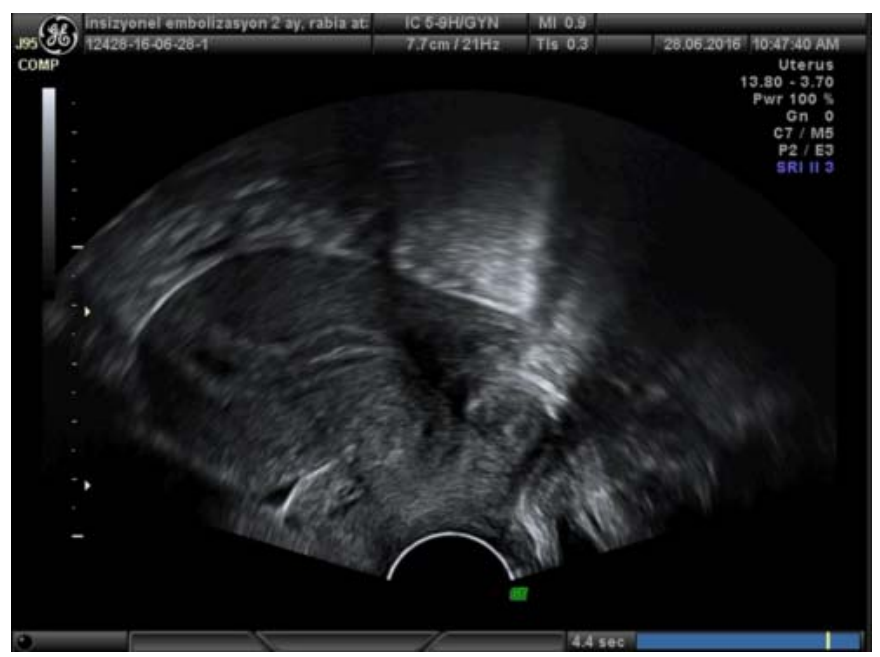

Figure 4: Post-embolization ultrasonography showing trilaminar endometrium

\section{Discussion}

Uterine arteriovenous malformation is an uncommon vascular disease, which usually occurs during reproductive ages. These potentially life-threatening lesions should be suspected in women with unexplained vaginal bleeding. The pattern of bleeding is intermittent and pouring. UAVM may be presented with life - threatening vaginal bleeding in $30 \%$ of patients. Congenital UAVM is extremely rare, and caused by abnormal development of uterine vessels. Acquired UAVM is more common, and presents secondary to previous surgery on the uterus, endometrial carcinomas, miscarriage, uterine infections, leiomyomas, endometriosis, intrauterine devices, and gestational trophoblastic diseases $(1,2,4)$.

Initial evaluation of UAVM is made with ultrasonography. These lesions may appear either as masses with multiple 
hypo/anechoic tubular like structures of varying sizes or as focal endometrial and myometrial thickenings. Vessels with malformations can be recognized with Doppler ultrasonography, MRI can show an enlarged uterus with multiple serpiginous flow-related signal void areas. CT angiography or MR angiography can easily detect the feeding arteries and draining the AVM. Digital subtraction angiography is still the gold standard in diagnostic imaging. However, the technique necessitates invasive approach. Doppler ultrasonography combined with CT angiography or MR angiography may be noninvasive diagnostic alternatives with high success $(2,3)$.

There are several treatment options for UAVMs. In hemodynamically stable patients expectant management, medical therapy, curettage, and uterine arteriovenous embolization can be applied. Even hysterectomy may be necessary for patients with severe bleeding $(5,8,9)$. Because UAVM is commonly diagnosed in women at childbearing age, angiographic embolization is the preferred treatment with favorable conditions. Our patient had no vaginal bleeding, she was referred to our hospital because of 7 weeks' scar pregnancy. We diagnosed and treated UAVM with UA embolization before bleeding.

Differential diagnosis includes retained products of conception, gestational trophoblastic disease, multilocular ovarian cysts, and pelvic varicosities. Ovarian cysts have no vascular appearance on Doppler ultrasonography, pelvic varicosities can easily be recognized by the appearance of normal venous vessels and prominent parametrial vessels. $\beta$ - hCG positivity is the main point for the differential diagnosis in patients with the gestational trophoblastic disease and retained products of conception $(1,4,10)$. In the present case $\beta$ - hCG was high because of 7 weeks scar pregnancy.

In conclusion, UAVM is a rare but potentially life - threatening condition. In suspected cases, UAVM can be diagnosed with Doppler ultrasonography, and can be treated successfully with either uterine artery embolization or uterine surgery. To the best of our knowledge, there are few case reports about ectopic pregnancy accompanied by an UAVM treated with uterine artery embolization $(6,7)$. In women of childbearing age, angiographic embolization should be considered as the first treatment option, and hysterectomy should be reserved for only life threatening conditions.

\section{References}

1. Schiller VL, Raft E, Linden R. Uterine arteriovenous malformation. AJR Am J Roentgenol. 1998;170(1):219-20.

2. Polat P, Suma S, Kantarcý M, Alper F, Levent A. Colour doppler ultrasound in the evaluation of uterine vascular abnormalities. Radiographics. 2002;22(1):47-53.

3. Huang MW, Muradali D, Thurston WA, Burns PN, Wilson SR. Uterine arteriovenous malformations: gray-scale and doppler ultrasound features with MR imaging correlation. Radiology. 1998;206(1):115-23.

4. Elia G, Counsell C, Singer SJ. Uterine artery malformation as a hidden cause of severe uterine bleeding. J Reprod Med. 2001;46(4):398-400.

5. Delotte J, Chevallier P, Benoit B, Castillon JM, Bongain A. Pregnancy after embolization therapy for uterine arteriovenous malformation. Fertil Steril. 2006;85(1):228.

6. Valsky DV, Hamani Y, Verstandig A, Yagel S. The use of 3D rendering, VCI-C, 3D power Doppler and B-flow in the evaluation of interstitial pregnancy with arteriovenous malformation treated by selective uterine artery embolization. Ultrasound Obstet Gynecol. 2007;29(3):352-5.

7. Kochhar PK, Sarangal M, Gupta U. Conservative management of cesarean scar pregnancy with uterine arteriovenous malformation: a case report. J Reprod Med. 2013;58(1-2):81-4.

8. Bhoil R, Raghuvanshi V, Basavaiah S. A case of congenital uterine arterio-venous malformation managed by hysterectomy. Pol J Radiol. 2015;(80):202-5.

9. Rosa E Silva JC, de Aguiar FM, de Sá Rosa E Silva AC, Candido Dos Reis FJ, Poli Neto OB, Nogueira AA. Conservative management of large uterine arteriovenous malformation: case report. Fertil Steril. 2008;90(6):24067.

10. Kido A, Togashi K, Koyama T, Ito H, Tatsumi K, Fujii S, et al. Retained products of conception masquerading as acquired arteriovenous malformation. J Comput Assist Tomogr. 2003;27(1):88-92. 